\title{
THE MEDTRONIC INTACT PORCINE VALVE: TEN-YEAR CLINICAL REVIEW
}

Brian G. Barratt-Boyes, MB, ChM, FRACS

Warwick M. Jaffe, MB, FRACP

Ralph M. Whitlock, MB, FRACP
Objective: Our objective was to assess the long-term mortality and morbidity associated with the Medtronic Intact valve (Medtronic, Inc, Minneapolis, Minn). Method: Between 1983 and 1996, 447 patients (280 men and 167 women) received 466 Intact valves: 280 aortic, 156 mitral, and 30 tricuspid. The mean age was 57 years (median 63 years), with 45\% younger than 60 years. The mean New York Heart Association class was 3.1. The follow-up was $98 \%$ complete and extended for 39 months (1-154 months) and 1324 patient-years. There were 32 valves at risk at 10 years after implantation. Doppler echocardiography was performed whenever possible in patients followed up for longer than 4 years (mean 8 years) after implantation. Results: Ten-year overall actuarial survival was 30\% $\pm 6 \%(14 \% \pm 7 \%$ for New York Heart Association classes IV-V and $39 \% \pm 8 \%$ for classes I-III). At 10 years freedom from infective endocarditis was $92 \% \pm 3 \%$, freedom from thromboembolism was $80 \% \pm 5 \%$, and freedom from nonstructural valve deterioration was $95 \% \pm 2 \%$. Ten-year freedom from explantation was $64 \% \pm 6 \%$, freedom from valve-related events was $51 \% \pm 6 \%$, and freedom from valve-related death was $88 \% \pm 3 \%$. There were 26 examples of structural valve deterioration, mainly caused by leaflet calcification (in 17 cases) and by buttress detachment (in 6 cases). In the aortic position at 10 years freedom from structural valve deterioration was $81 \% \pm 9 \%$, but with only 1 event in patients older than 40 years (freedom $92 \% \pm$ $8 \%$ ) and $100 \%$ freedom in patients older than 60 years. There was also $100 \%$ freedom from structural valve deterioration in the tricuspid position. In the mitral position freedom was $65 \% \pm 8 \%$, with no significant difference between age groups. Conclusion: The Intact valve provides superior results in the aortic position in patients older than 40 years and in the tricuspid position at all ages. ( $J$ Thorac Cardiovasc Surg 1998;116:1005-14)
$\mathrm{T}_{\mathrm{h}}^{\mathrm{h}}$ Medtronic Intact valve (Medtronic, Inc, Minneapolis, Minn) is a porcine valve that is fixed in glutaraldehyde at zero pressure and mounted on a flexible acetyl copolymer stent. Zero-pressure fixation,

From the Departments of Cardiac Surgery, Cardiology and Clinical Physiology, and Statistics, Green Lane Hospital, Auckland, New Zealand.

Supported by a grant from Medtronic Inc, Heart Valve Division.

Received for publication May 6, 1998; revisions requested July 1, 1998; revisions received July 29, 1998; accepted for publication Aug 6, 1998.

Address for reprints: Sir Brian Barratt-Boyes, PO Box 51, Waiwera, Auckland 1240, New Zealand.

*Medtronic, Inc, Minneapolis, Minn.

Copyright (C) 1998 by Mosby, Inc.

$0022-5223 / 98 \$ 5.00+0 \quad \mathbf{1 2 / 1 / 9 3 7 7 7}$ in contrast to fixation at pressures of at least $2 \mathrm{~mm} \mathrm{Hg}$, has been shown to preserve nearly normal extensibility of the leaflet collagen, which allows the leaflet to open fully without kinking. ${ }^{1}$ This characteristic is expected to increase postimplantation durability. Toluidine blue has been employed as an anticalcification agent.

This device was released for clinical use by Xenotech Inc (Irvine, Calif) in 1983 and was first implanted at Green Lane Hospital in August of that year. Since then the valve, renamed the Intact by Medtronic in 1986, has been used by us for patients in whom a stent-mounted porcine valve was considered preferable to other devices. We have published 3 previous follow-up reports, with the most recent an 8 -year review. ${ }^{2-4}$ Since then the database has been enlarged to include patients operated on until the end of 1996. 
Table I. Valve use by position

\begin{tabular}{lccc}
\hline & \multicolumn{3}{c}{ Valve position } \\
\cline { 2 - 4 } Valve size $(\mathrm{mm})$ & Aortic & Mitral & Tricuspid \\
\hline 23 & 76 & 0 & 0 \\
25 & 96 & 0 & 0 \\
27 & 65 & 5 & 0 \\
29 & 42 & 27 & 2 \\
31 & 0 & 71 & 7 \\
33 & 0 & 48 & 17 \\
35 & 1 & 5 & 4 \\
Total & 280 & 156 & 30 \\
\hline
\end{tabular}

Table II. Valve distribution by age and site

\begin{tabular}{lccccr}
\hline & & & & \multicolumn{2}{c}{ Total } \\
\cline { 3 - 6 } Decade & Aortic & Mitral & Tricuspid & No. & $\%$ \\
\hline $10-19$ y & 2 & 10 & 3 & 15 & 3 \\
$20-39$ y & 25 & 38 & 8 & 71 & 15 \\
$40-59$ y & 62 & 50 & 10 & 122 & 26 \\
$60-82$ y & 191 & 58 & 9 & 258 & 55 \\
Total & 280 & 156 & 30 & 466 & \\
\hline
\end{tabular}

\section{Patients and methods}

Study group. Between 1983 and the end of 1996, 447 patients (280 men and 167 women) received 466 Intact valves. There were 9 multiple Intact valve replacements, and 10 patients received a second Intact valve at reoperation. These 10 were reentered into the data set at that time. The total number of operations was 456 .

Two hundred eighty valves were inserted in the aortic position, 156 were inserted in the mitral position, and 30 were inserted in the tricuspid position. The valve sizes are shown in Table I. Valve distribution by patient age at implantation and position is given in Table II, and the mean, median, and range of ages are shown in Table III. Only 55\% were older than 60 years. Patients undergoing aortic replacement were older than mitral and tricuspid valve recipients $(P=.0001)$. Most younger patients were either New Zealand Maoris or Polynesians thought unlikely to be reliable in taking anticoagulants or Polynesians returning to remote Pacific islands where anticoagulant control was not possible. These ethnic groups comprised $31 \%$ of the patients and $71 \%$ of those younger than 40 years.

Twelve patients were in New York Heart Association (NYHA) class I, 87 were in class II, 207 were in class III, 138 were in class IV, and 12 were in class $\mathrm{V}$ (unable to leave bed or undergoing emergency operations). The mean NYHA class was 3.1 .

The procedure involved a first operation with a single valve replacement in $65 \%$ of patients. Previous valve operations had been undertaken in $18 \%$ of patients and concurrent operations (coronary artery bypass grafting or resection of ascending aortic arch aneurysm or left ventricular aneurysm)
Table III. Age in years at operation

\begin{tabular}{lccc}
\hline \multicolumn{1}{c}{ Valve site } & Mean & Range & Median \\
\hline Aortic $(\mathrm{n}=280)$ & 63 & $19-82$ & 68 \\
Mitral $(\mathrm{n}=156)$ & 50 & $12-78$ & 53 \\
Tricuspid $(\mathrm{n}=30)$ & 46 & $11-73$ & 46 \\
Total $(\mathrm{n}=466)$ & 57 & $11-82$ & 63 \\
\hline
\end{tabular}

were performed in $33 \%$ of patients. Concurrent replacement or repair of another valve was undertaken in $20 \%$. The additional valve replacement was an Intact in 9 cases, an aortic homograft in 39 cases (making a total tissue valve replacement), and a prosthetic valve in 14 cases. The Intact valve was confined to the tricuspid position in all but 1 of the last group of patients.

Management. The valves were inserted by 8 different surgeons, usually with interrupted sutures. All patients received antibiotic prophylaxis given immediately before and usually for 3 days after operation. Routine warfarin anticoagulation was started on the second postoperative day and discontinued after 6 weeks, except when there was chronic atrial fibrillation or a prosthetic valve in another site, in which case it was permanent. The aim was to maintain the international normalized ratio between 2 and 3 .

Follow-up. Follow-up was undertaken during the second half of 1996 and was $98 \%$ complete. It extended for a mean of 39 (1-154) months, corresponding to 1324 patient-years.

Patients with a shorter follow-up than 3 years were reviewed by their general practitioners unless symptoms were present, in which case they were seen by a cardiologist. Most of those with follow-up beyond 3 years were seen by a cardiologist, and echocardiography was performed whenever possible. All videotapes were reviewed by 1 of us (W.M.J.) without knowledge of the patient's clinical status.

A Sonos 2000 Doppler echocardiographic unit (Hewlett Packard Company, Andover, Mass) was used. Multiple windows were used to record aortic velocity. Left ventricular outflow velocity was measured with pulsed-wave Doppler ultrasonography. Mean mitral and aortic gradients were calculated by planimetry of 3 waveforms for patients in sinus rhythm and of 10 waveforms if atrial fibrillation was present. The mean aortic gradient was corrected for the left ventricular outflow gradient. The equation of continuity was used to calculate aortic valve area. Mitral valve area was calculated by the pressure half time method. The presence of regurgitation was assessed by color flow imaging.

Data analysis. Patient survival and other events were analyzed with Kaplan-Meier actuarial curves, and comparisons were made with the Mantel-Haenszel log-rank test. These curves are presented at 10 years of follow-up, because beyond that time the numbers at risk were too small to be significant. Because only 9 patients had more than 1 Intact valve, a multivalve category was not included except in the case of patient survival, in which the multivalve category included patients with replacement of more than 1 valve 
Table IV. Causes of death

\begin{tabular}{lrr}
\hline \multicolumn{1}{c}{ Cause of death } & No. & $\%$ \\
\hline Congestive heart failure & 16 & 17 \\
Myocardial infarction & 12 & 13 \\
Infective endocarditis & 6 & 7 \\
Stroke & 9 & 10 \\
Sudden death/arrhythmia & 21 & 23 \\
Bleeding & 4 & 4 \\
Cancer & 11 & 12 \\
Miscellaneous noncardiac & 11 & 12 \\
Unknown & 2 & 2 \\
Total & 92 & 100 \\
\hline
\end{tabular}

regardless of the type of device. For events other than survival the analysis considered the 466 valves rather than the 447 patients. The 2-tailed Fisher exact test was used for comparisons of categoric data.

\section{Results}

Survival. The 30-day mortality rate was $8.9 \%$ (40 patients). The risk increased with age increment in double decades $(P=.004)$, and there was a nonsignificant trend toward higher mortality rates among patients undergoing associated coronary artery bypass grafting or double valve replacement. There were 5 deaths among the 13 patients in NYHA class V (38\%).

There were 92 subsequent deaths (20\%), all but 4 of which occurred within 10 years of operation. Autopsy was performed in only 9 cases. The probable causes of death are listed in Table IV. The designation sudden death includes death during sleep and from known arrhythmia. Although some of these may have been embolic in origin, none is included under the category of thromboembolism because most were probably from arrhythmia. Before the operation, 15 of the 21 patients with sudden deaths had severe aortic valve disease, associated in 11 cases with severe left ventricular hypertrophy. Nine patients were assumed to have thromboembolic stroke and 2 others were assumed to have hemorrhagic stroke in association with an extremely elevated international normalized ratio (none underwent a brain scan). Eighteen of these late deaths can be considered to be related to the study valve ( 9 from thromboembolism, 5 from infective endocarditis, and 4 from anticoagulant-related hemorrhage). In addition, pathologic condition of the study valve may have contributed to death in 3 cases of patients dying of heart failure (perivalvular leakage in 1 case and mitral stenosis in 2 cases).

Actuarial survival at 10 years was $30 \% \pm 6 \%$, compared with an actuarial survival of $70 \%$ in a matched

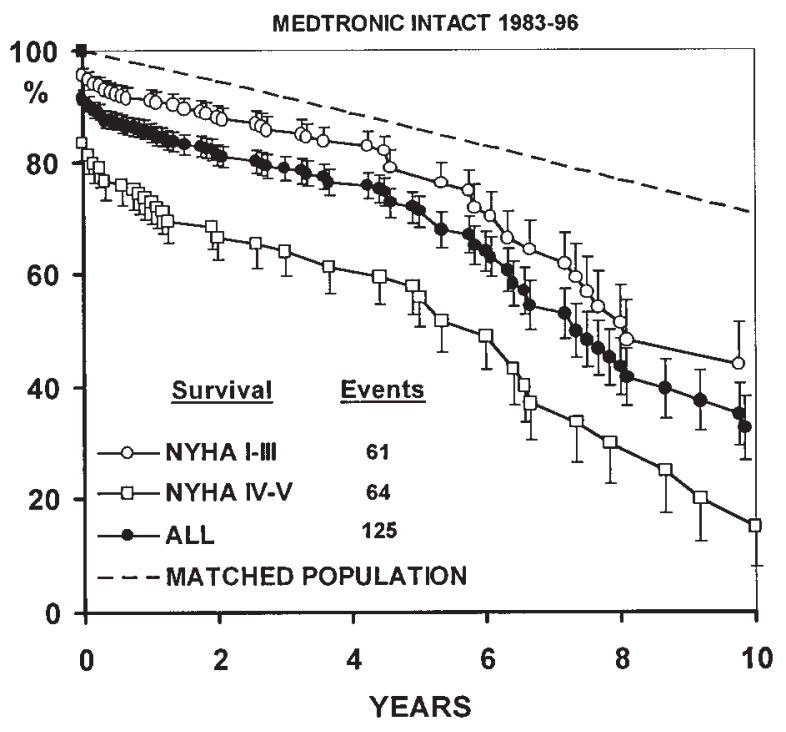

Fig 1. Actuarial survival of all patients, those in different NYHA classes, and a matched general population. The bars represent \pm 1 standard error (70\% confidence limits).

general population (Fig 1). When in-hospital deaths were excluded, the slope of the curve was similar to that of the general population for the first 5 years but then showed a more rapid decline. When noncardiac deaths were excluded, survival was $41 \% \pm 7 \%$. There was no significant difference in survival between patients receiving isolated valve and multivalve replacements, nor between patients undergoing isolated aortic and isolated mitral valve replacement, nor between patients with or without coronary artery bypass grafts. Survival among patients in NYHA classes IV and V was $14 \% \pm 7 \%$, compared with a survival of $39 \% \pm 8 \%$ among patients in classes I to III ( $P=$ .001 , Fig 1).

Infective endocarditis. Infective endocarditis occurred on 13 Intact valves: 7 aortic, 5 mitral, and 1 tricuspid (in which the primary focus was on a leftsided prosthetic valve). Six underwent reoperation, with 2 deaths. The actuarial freedom from this event at 10 years was $92 \% \pm 3 \%$.

Thromboembolism, valve thrombosis, and anticoagulant hemorrhage. Thirty-four patients were classified as having thromboembolism, including all those with permanent and transient stroke. None of these patients had a prosthetic valve at another site. The incidences were similar between patients with aortic and mitral valve replacement.

There was 1 example of thrombosis of an aortic Intact valve; this was recognized 6 months after im- 


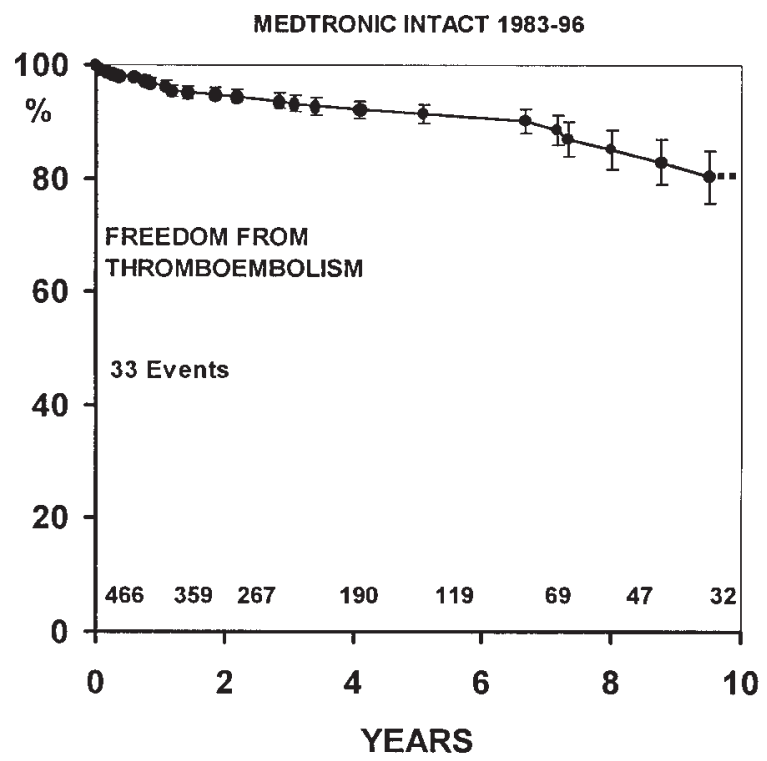

Fig 2. Actuarial freedom from thromboembolism and valve thrombosis. The bars represent \pm 1 standard error ( $70 \%$ confidence limits). The dotted line indicates no further events. The number at risk is shown.

plantation and the valve was successfully replaced. Full hematologic studies demonstrated the presence of lupus anticoagulant. The actuarial freedom from thromboembolism (including the 1 case of valve thrombosis) was $80 \% \pm 5 \%$ at 10 years (Fig 2).

There were 4 examples of anticoagulant-related bleeding associated with a prolonged international normalized ratio. All were fatal, 2 as a result of stroke. Minor incidents of bleeding not necessitating hospitalization were not recorded.

Structural valve deterioration. There were 26 cases of structural valve deterioration, with an actuarial freedom of $74 \% \pm 6 \%$ at 10 years, at which time there were 32 valves at risk. The valve site, mechanism, and patient age are detailed in Table V. Most (17) were due to diffuse leaflet calcification, usually producing pure stenosis but occasionally with tearing in the commissural region and incompetence. In all but 3 instances these patients were younger than 40 years. Calcification was more common in the mitral position than in the aortic position. Leaflet tearing without calcification was rare. The most common cause of pure incompetence was buttress detachment (commissural dehiscence or stent post dehiscence), which occurred in 5 mitral valves but in only 1 aortic valve. This process involved detachment of the aortic wall remnant of the valve from the polyethylene terephthalate fabric (Dacron) covering the stent post as a result of tearing out of the sutures from the aortic wall. It produced prolapse of the commissural region
Table V. Structural valve deterioration

\begin{tabular}{lcccc}
\hline \multicolumn{1}{c}{ Failure mode } & $<20 y$ & $20-39 y$ & $40-59 y$ & $\geq 60 y$ \\
\hline Aortic position (No.) & 2 & 25 & 62 & 191 \\
Calcification & 0 & 3 & 1 & 0 \\
Buttress detachment & 0 & 0 & 1 & 0 \\
Mitral position (No.) & 11 & 36 & 46 & 54 \\
Calcification & 3 & 7 & 0 & 2 \\
Tear without & 0 & 0 & 0 & 2 \\
$\quad$ calcification & & & & \\
Buttress detachment & 0 & 2 & 1 & 2 \\
Perforation muscle & 0 & 0 & 0 & 1 \\
$\quad$ shelf & 3 & 9 & 11 & 9 \\
Tricuspid position (No.) & 3 & 1 & 0 & 0 \\
Calcification & 0 & $13(19 \%)$ & $3(3 \%)$ & $7(3 \%)$ \\
Totals (No.) & $3(19 \%)$ & & & \\
\hline
\end{tabular}

and of the cusp free edge (Fig 3). Two posts were affected in 1 case. The earliest occurrence was at 75 months after implantation, and occurrences were seen thereafter at fairly regular intervals until 136 months. Actuarial freedom from this event at 10 years in the mitral position was $85 \% \pm 7 \%$ (Fig 4). There was 1 example of perforation through the muscular shelf at the base of the right aortic leaflet; this was associated with hemolysis.

Actuarial freedom from structural valve deterioration in the aortic position was $81 \% \pm 9 \%$ at 10 years (Fig 5). There was 1 event beyond 10 years in a 49-year-old patient as a result of buttress detachment. There were 3 events in the 27 patients younger than 40 years, yielding an actuarial freedom of $33 \% \pm 26 \%$ at 7 years, and 1 event in patients older than 40 years, yielding an actuarial freedom of $92 \% \pm 8 \%$ at 10 years (Fig $6, P=.0005$ ). Actuarial freedom from structural valve deterioration was $100 \%$ at 10 years in the 192 patients 60 years old or older.

In the mitral position actuarial freedom from structural valve deterioration at 10 years was $65 \% \pm 8 \%$ (Fig 5). There was no significant difference between age groups (Fig 7). The actuarial freedoms from structural valve deterioration at 10 years were $50 \% \pm 12 \%$ for patients younger than 40 years and $76 \% \pm 9 \%$ for those 40 years old and older $(P=.1)$. An additional 6 events occurred beyond 10 years, 4 in patients 20 to 37 years old and 2 in patients 60 and 63 years old. Structural valve deterioration was unrelated to valve size $(P=.39)$.

In the tricuspid position the numbers were small, but freedom from structural valve deterioration at 10 years was $100 \%$ (Fig 5). There was 1 valve removed beyond 10 years for calcific stenosis; this was done at 127 months in a 31-year-old patient.

Nonstructural valve deterioration. The category of nonstructural valve deterioration comprises 8 perivalvular leaks (5 mitral and 3 aortic) and an entrapment of 1 pillar of a valve in the tricuspid position beneath a 


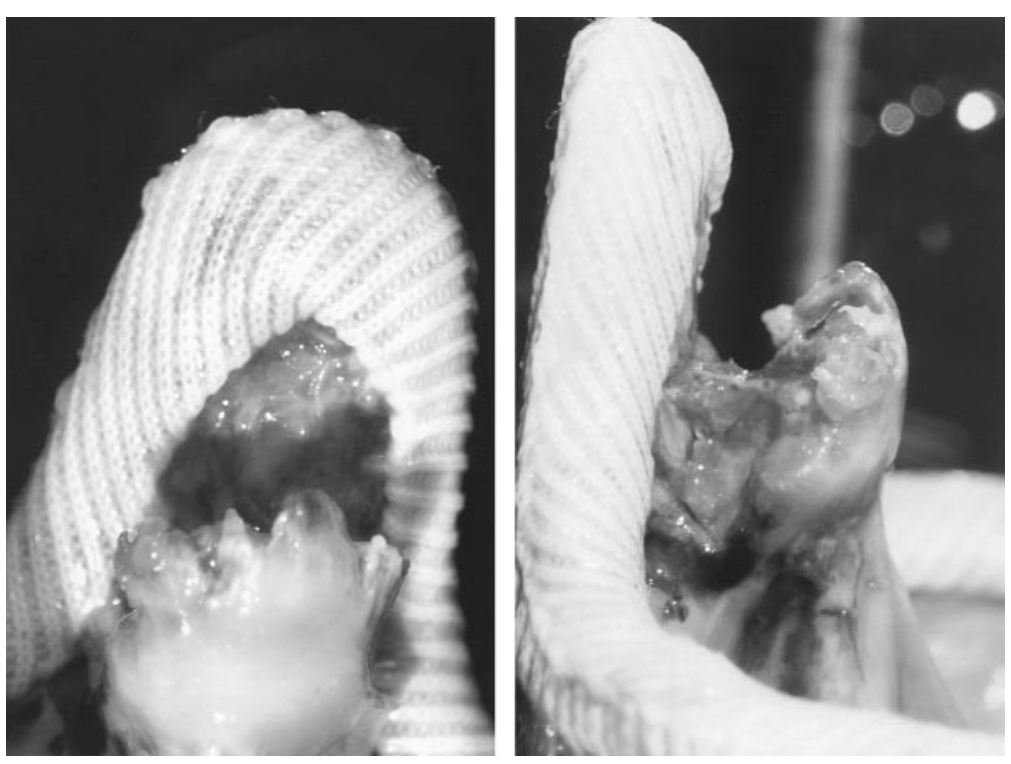

Fig 3. Photographs of an Intact valve removed because of buttress detachment. Stent post viewed en face and laterally.

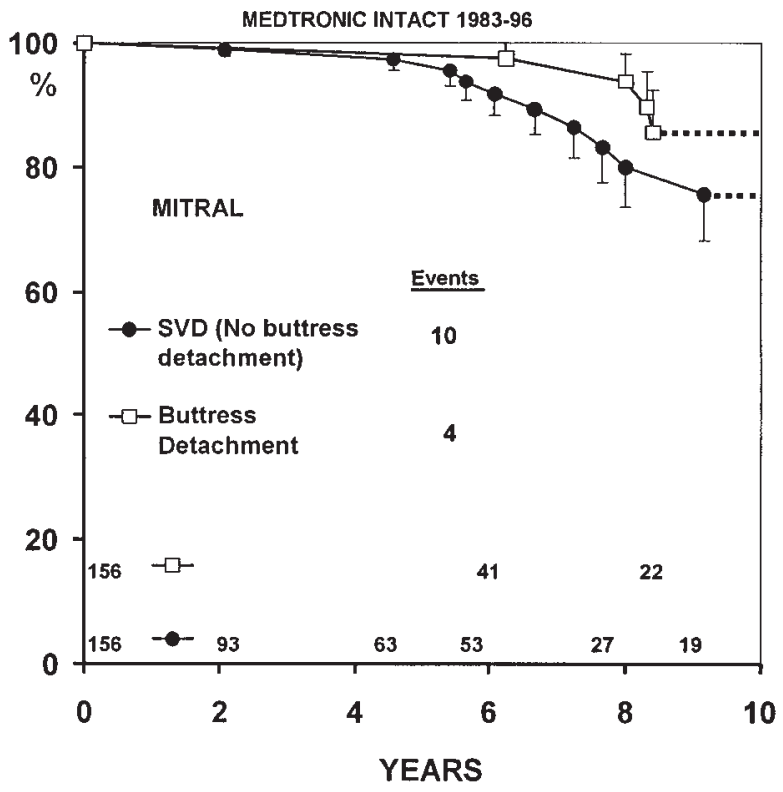

Fig 4. Actuarial freedom from buttress detachment in the mitral position. The bars represent \pm 1 standard error $(70 \%$ confidence limits). The dotted lines indicate no further events. The numbers at risk are shown.

large trabeculation in the right ventricle, which produced leaflet thickening and incompetence. Freedom from this event was $95 \% \pm 2 \%$ at 10 years.

Explantation. Explantation was undertaken on 47 occasions (Table VI), with 3 in-hospital deaths (6.3\%).

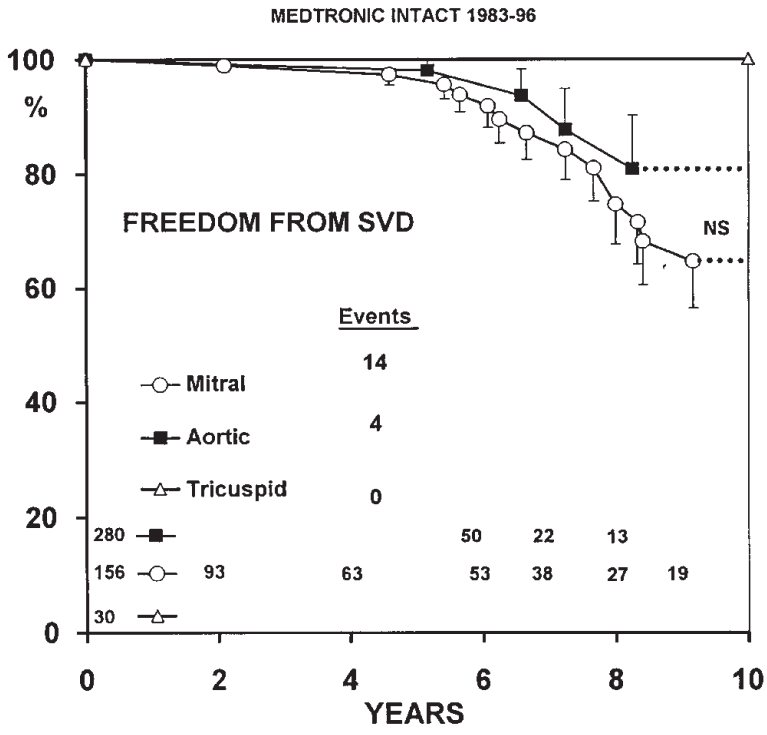

Fig 5. Actuarial freedom from structural valve deterioration (SVD) in the aortic, mitral, and tricuspid positions. The bars represent \pm 1 standard error (70\% confidence limits). The dotted lines indicate no further events. The numbers at risk are shown. NS, Not significant.

Five of the valves were functioning normally and were replaced with a prosthetic device at the time of reoperation for a nonstudy valve in the hope of avoiding further reoperation. Freedom from this event at 10 years was $64 \% \pm 6 \%$, excluding the 5 normal valves. Ex- 


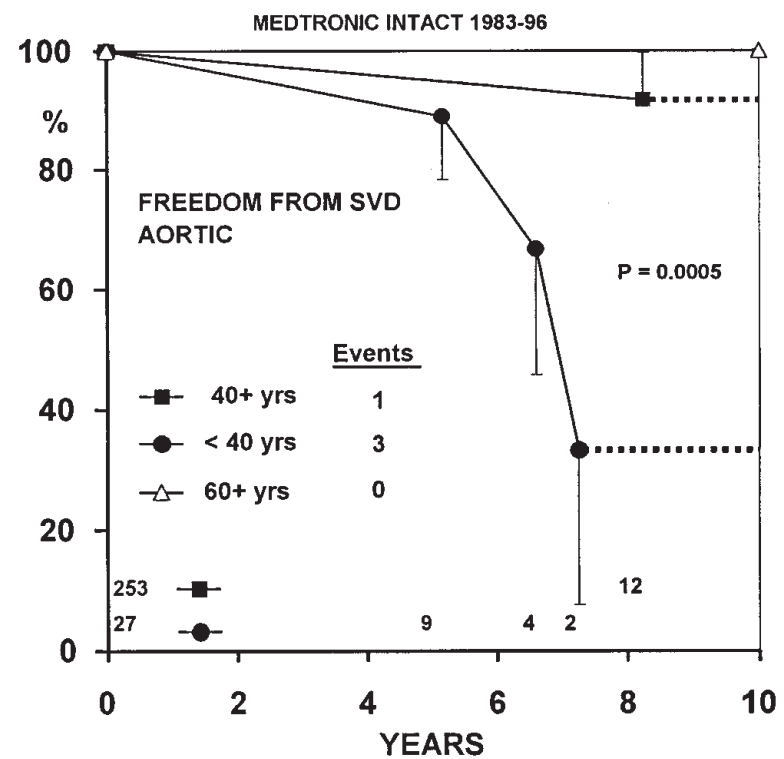

Fig 6. Actuarial freedom from structural valve deterioration (SVD) in the aortic position according to patient age older than 40 years and older than 60 years at implantation. The bars represent \pm 1 standard error ( $70 \%$ confidence limits). The dotted lines indicate no further events. The numbers at risk are shown.

Table VI. Explantation

\begin{tabular}{lccc}
\hline Cause & Aortic & Mitral & Tricuspid \\
\hline Structural valve deterioration & 5 & 20 & 1 \\
Perivalvular leakage, etc & 3 & 5 & 1 \\
Infective endocarditis & 3 & 2 & 1 \\
Valve thrombosis & 1 & 0 & 0 \\
Normal & 2 & 3 & 0 \\
Totals & 14 & 30 & 3 \\
\hline
\end{tabular}

plantation was more common in the mitral position than in the aortic position (Fig 8).

Valve-related events. Actuarial freedom from all valve related events at 10 years was $51 \% \pm 6 \%$. Actuarial freedom from valve-related death was $88 \% \pm 3 \%$ (Fig 9).

Echocardiography. Doppler echocardiographic examination was requested for all patients with a follow-up beyond 3 years. In fact, echocardiography was consented to by only $63(65 \%)$ of patients with aortic Intact valves, $29(41 \%)$ of those with mitral Intact valves, and $2(13 \%)$ of those with tricuspid Intact valves at a mean of 8 years (4-11 years) years after implantation. Because all patients with symptoms accepted the necessity for this examination, however, we are confident that no examples of severe study valve lesions were omitted.

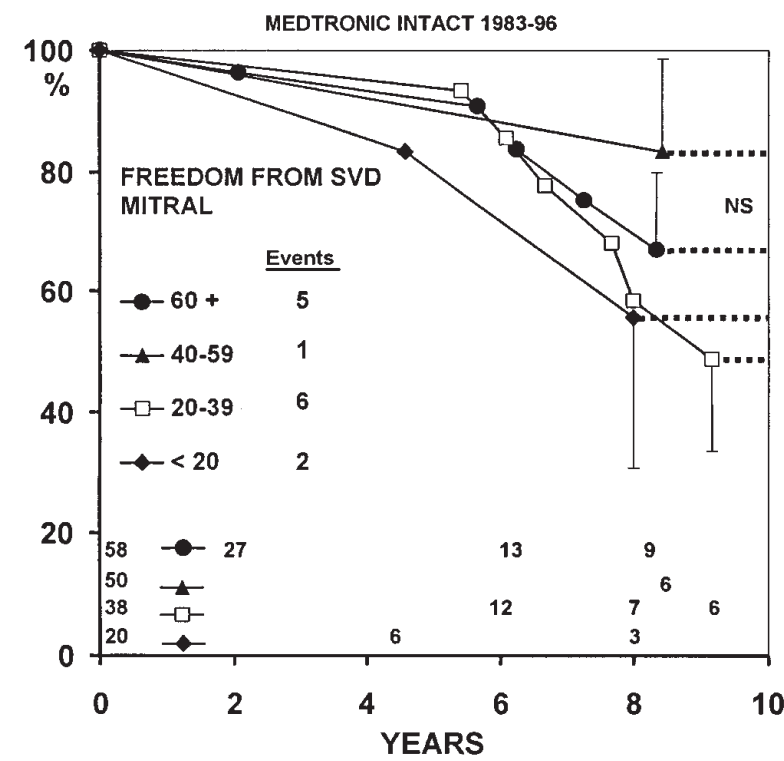

Fig 7. Actuarial freedom from structural valve deterioration (SVD) in the mitral position according to patient age in decades at implant. The bars represent \pm 1 standard error (70\% confidence limits). The dotted lines indicate no further events. The numbers at risk are shown. NS, Not significant.

In the aortic position (Table VII) moderate leaflet thickening with a mean pressure gradient of $30 \mathrm{~mm} \mathrm{Hg}$ and an effective orifice area of $1.0 \mathrm{~cm}^{2}$ was noted in a single 69-year-old patient, who was in NYHA class II. One other 69-year-old patient, who was in NYHA class I, had moderate stenosis (gradient $40 \mathrm{~mm} \mathrm{Hg}$, effective orifice area $1.0 \mathrm{~cm}^{2}$ ). There were no examples of severe stenosis, significant leaflet calcification, or significant aortic regurgitation.

In the mitral position (Table VII) there were 2 examples of moderate leaflet thickening, 1 associated with stenosis and the other with moderate central regurgitation. The patient with stenosis (gradient $10 \mathrm{~mm} \mathrm{Hg}$, effective orifice area $0.81 \mathrm{~cm}^{2}$ ) also had moderate leaflet calcification but remained in NYHA class I. The second patient with moderate incompetence had a perivalvular leak with normal leaflets and was also in NYHA class I.

The 5 patients with echocardiographic abnormalities are not included in the actuarial analysis of valve morbidity.

Symptom status. Among surviving patients at final review, 192 were in NYHA class I, 46 were in class II, 10 were in class III, and 2 were in class IV ( 1 because of severe angina and 1 with a tricuspid Intact valve because of congestive heart failure). The mean NYHA class was 1.3. 


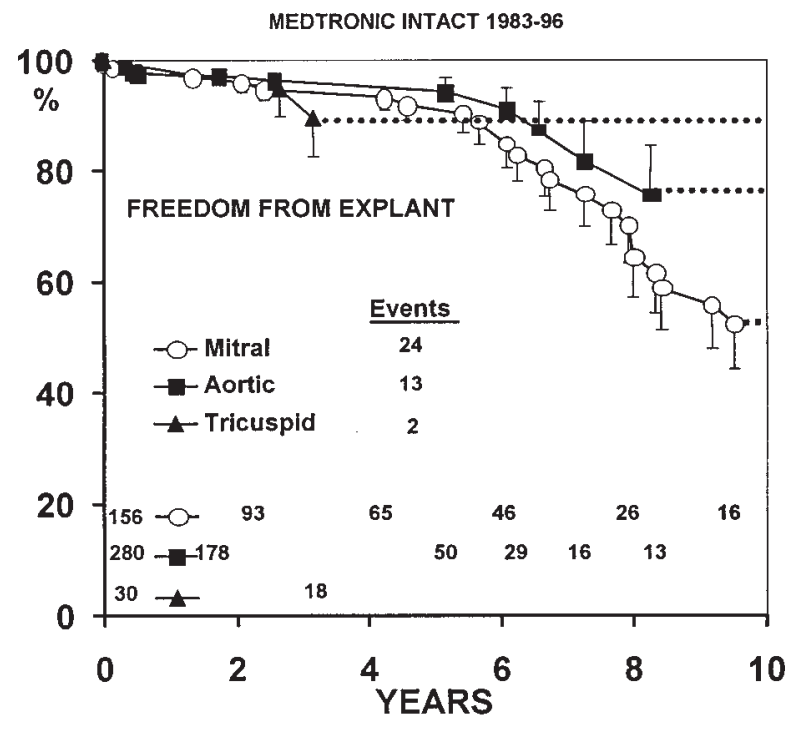

Fig 8. Actuarial freedom from explantation, excluding 5 normal valves. The bars represent \pm 1 standard error $(70 \%$ confidence limits). The dotted lines indicate no further events. The numbers at risk are shown.

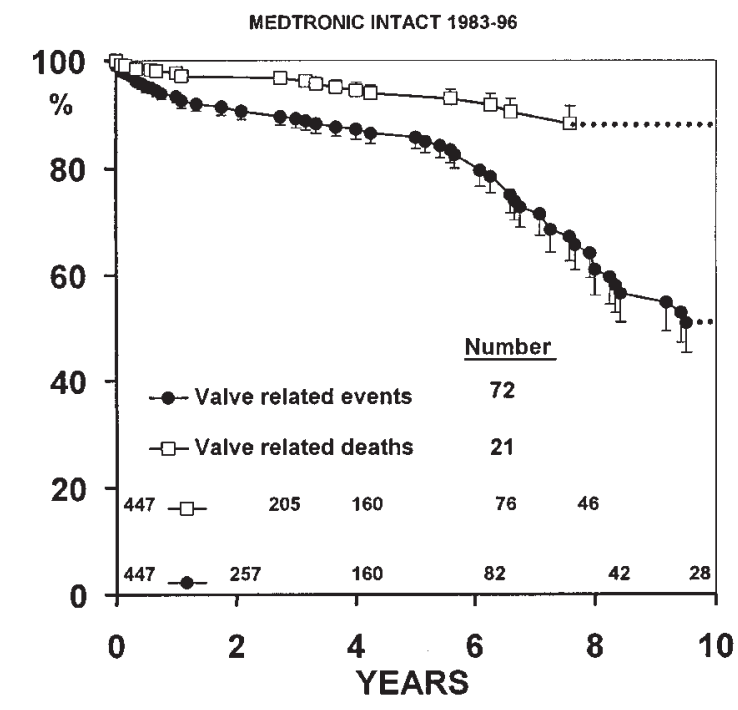

Fig 9. Actuarial freedom from valve-related events and valverelated deaths. The bars represent \pm 1 standard error $(70 \%$ confidence limits). The dotted lines indicate no further events. The numbers at risk are shown.

Table VII. Echocardiographic data obtained 8 (4-11) years after implantation

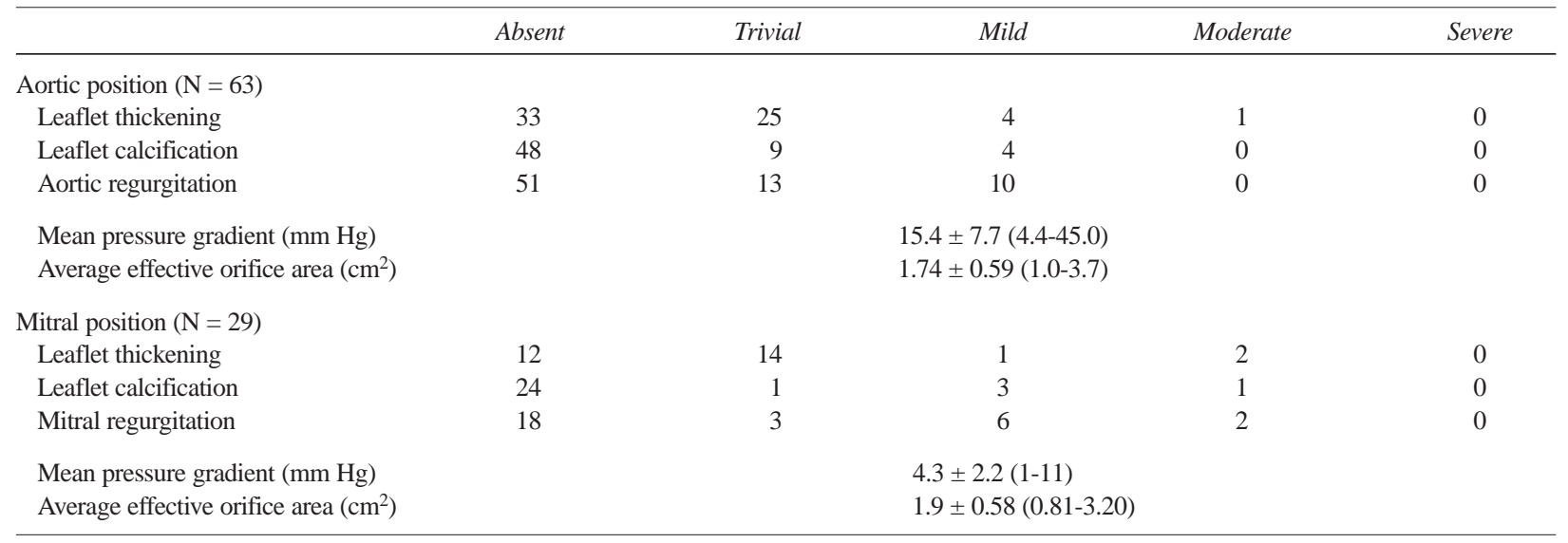

\section{Discussion}

This report provides information to 10 years after implantation on stented porcine valves fixed in glutaraldehyde at zero pressure. The 32 valves at risk at 10 years provide sufficient data from which to draw tentative conclusions at this interval, particularly in the aortic position and particularly with respect to age at implantation.

Although zero-pressure fixation is the key factor that differentiates the Intact valve from porcine bioprostheses fixed under pressure, a number of other design fac- tors can affect the result in stented valves and thus make comparisons between bioprostheses difficult. For example, poor stent design that distorts the leaflets will result in earlier failure. A valve that is fixed under pressure, with the leaflets closed and the aorta distended, is easier to mount inside a stent than is a zero-pressure fixed valve. Moreover, the nondistended aortic root and inflow anulus of zero-pressure fixed tissue downwardly sizes the valve slightly and produces crowding of tissue and suboptimal leaflet motion. ${ }^{5}$ This can be overcome by fixing the aortic root at a physiologic pressure 
in combination with zero-pressure fixation of the leaflets, a technology that is now available in stented ${ }^{6}$ and nonstented porcine valves. ${ }^{7,8}$

There is no obvious explanation for the lower than expected 10-year actuarial survival of $30 \%$, nor for the finding of similar mortality rates between patients with isolated aortic and isolated mitral valve replacement and between those with isolated valve and multiple valve replacement. A multivariate analysis to assess the numerous risk factors ${ }^{9}$ has not been done, nor would it be of great value because left ventricular function has not been assessed in most cases. In other studies of stented and prosthetic valves, survival has not been related to the type of replacement device ${ }^{10}$ and deaths related to the study valve in this series were acceptably low (actuarial freedom of $88 \% \pm 3 \%$ ).

Possible factors related to the low survival include the significantly lower survival of a matched New Zealand population compared with a matched US population, the poor compliance of Maori and Polynesian patients with postoperative supervision, and the long surgical waiting lists at Green Lane Hospital, the result of inadequate state funding. This last has resulted in a situation in which patients must have severe symptoms before being accepted for their initial operation and is in marked contrast to North American practice, in which patients are accepted earlier in their course, before the onset of significant left ventricular damage. It must also be emphasized that NYHA functional class correlates poorly with left ventricular function, the most important risk factor, particularly in aortic valve disease. ${ }^{9}$

These data are similar to those from other reports of stented porcine valve implants with respect to the incidence of infective endocarditis, nonstructural valve dysfunction, and thromboembolism. The single example of valve thrombosis occurred in the presence of lupus anticoagulant. ${ }^{11}$

Structural valve deterioration is the most important parameter of durability. The failure mode was leaflet calcification in 17 of the 26 valves. Only 3 of these 17 failures occurred in patients older than 40 years (Table $\mathrm{V})$, indicating a much higher incidence in the first 4 decades as would be expected ${ }^{12}$ but a low incidence in both the 40- to 59-year and the 60-year and older age groups. This suggests that the practice of confining the use of bioprostheses to patients older than 65 to 70 years may no longer be appropriate when zero-pressure fixed tissue is used, because zero-pressure fixation may play an important part in the low incidence by creating a softer leaflet that does not kink on opening. ${ }^{13}$ Any additional preventive effect from toluidine blue impregnation of the leaflet is uncertain.
An unexpected failure mode was buttress detachment, which was more common in the higher closing pressure mitral position. This phenomenon, which is not age related, has been reported with stent-mounted homografts, ${ }^{14,15}$ with the low-pressure fixed supraannular Carpentier-Edwards valve, ${ }^{16,17}$ and rarely with high-pressure fixed valves. ${ }^{18}$ Factors predisposing toward buttress detachment include excess thinning of the aortic wall before mounting the valve on the stent, ${ }^{16}$ increased loading of the affected post because of mismatch of valve and stent, inadequate suturing techniques during mounting, and, possibly in the case of the Intact valve, zero-pressure fixation of the aortic wall. The hazard function of buttress detachment is uncertain because of insufficient numbers, but it has not produced significant valve incompetence from leaflet prolapse before the seventh year of follow up. It is characteristically associated with absence of host tissue fibrous overgrowth onto the aorta at the top of the post. This overgrowth is almost always present and securely attaches the valve to the stent, preventing its detachment. ${ }^{18}$

Neither in this series nor in the larger Canadian experience ${ }^{19}$ did early cusp tearing occur in the aortic position. The most likely cause of this failure mode ${ }^{20}$ is tearing of the soft leaflet by long, stiff suture ends protruding from the sewing ring. ${ }^{21}$ Early cusp tearing could also be due to leaflet abrasion against the Dacron stent covering, particularly if the valve is too large for the stent and the leaflet tissue is redundant as a result. Proper quality control should avoid this. ${ }^{22}$

The incidence of structural valve deterioration is strikingly low in the aortic position in patients older than 40 years, with an actuarial freedom at 10 years of 92\% (1 event from calcification in 253 valves). Actuarial freedom at 10 years was $100 \%$ in patients older than 60 years. These results are reinforced by similar findings after 9 years in the Canadian experience. ${ }^{19}$ The incidence of structural valve deterioration in the mitral position is no better than for other porcine valve types and is affected unfavorably by buttress detachment. This reflects the known poorer performance of a semilunar valve in this position. Although it is not statistically significant, it is interesting to note that the structural valve deterioration rate was lowest in the 40- to 59-year age group and that there was a freedom from deterioration of approximately 55\% at 8 years in the 58 patients younger than 40 years.

The Doppler echocardiographic data obtained 8 years (4-11 years) after the operations confirm that valves, particularly in the aortic position, are not deteriorating significantly during this time frame. The 
mean transvalvular gradient for sizes 23 to $27 \mathrm{~mm}$ of $15 \pm 7.7 \mathrm{~mm} \mathrm{Hg}$ compares favorably with that of $13 \pm$ $3 \mathrm{~mm} \mathrm{Hg}$ measured 4 years after implantation in these Intact valves. ${ }^{3}$ Other studies indicate an acceptable gradient even in $21-\mathrm{mm}$ diameter valves. ${ }^{23}$ These gradients are produced by relatively bulky inflow annular tissue in association with the leaflet hinging a few millimeters away from its point of attachment to the aortic wall.

Patient age is by far the strongest incremental risk factor for structural valve deterioration, ${ }^{12,24}$ with almost all series of tissue valves showing a much lower incidence among elderly patients than among younger patients. In making comparisons between the Intact valve and other tissue valves, the most sensitive index may be the age before which the structural valve deterioration incidence increases significantly. In the aortic position for the standard high-pressure fixed Carpentier-Edwards and Hancock valves this would appear to be approximately 70 years, ${ }^{12,25}$ and for the low-pressure fixed supra-annular Carpentier-Edwards valve, ${ }^{16,26}$ the Carpentier-Edwards pericardial valve, ${ }^{27,28}$ and the low-pressure fixed Hancock II valve ${ }^{29,30}$ it is approximately 65 years. In contrast, the cutoff point for the Intact valve in this series would appear to be 40 years $(P=.0005$, Fig 6$)$.

The effect of age on structural valve deterioration is most closely related to the incidence of calcification in glutaraldehyde-treated tissue. Thus factors that decrease calcification should improve durability, particularly in younger patients. Combined with zeropressure fixation of the leaflets and pressure fixation of the aortic root ("physiologic fixation"), such factors should provide a superior tissue valve that can be used with more confidence in younger patients.

We gratefully acknowledge permission to include patients operated upon by Drs A. R. Kerr, K. G. Graham, D. Hill, C. Robinson, P. J. Raudkivi, D. Haydock, and P. Milsom, and we thank P. Whiting, H. Nisbett, and M. Vedder for their assistance in data collection and analysis.

\section{REFERENCES}

1. Mayne AS, Christie GW, Smaill BH, Hunter PJ, Barratt-Boyes BG. An assessment of the mechanical properties of leaflets from four second-generation porcine bioprostheses using biaxial testing techniques. J Thorac Cardiovasc Surg 1989;98:170-80

2. Jaffe WM, Barratt-Boyes BG, Gavin JB, Coverdale HA, Neutze JM. Early follow-up of patients with the Intact porcine valve: a new cardiac bioprosthesis. J Thorac Cardiovasc Surg 1989;98: 181-92.

3. Barratt-Boyes BG, Ko PH, Jaffe WM. The zero pressure fixed Medtronic Intact porcine valve: clinical results over a six year period including serial echocardiographic assessment. J Card Surg 1991;6(suppl):606-12.
4. Barratt-Boyes BG, Jaffe WM, Ko PH, Whitlock RM. The zero pressure fixed Medtronic Intact valve: an 8.5 year review. J Heart Valve Dis 1993:2:604-11.

5. Lockie KJ, Fischer J, Juster NP, Davies GA, Watterson K. Biomechanics of glutaraldehyde-treated porcine aortic roots and valves: an investigation of the effect of predilatation of the elastic aortic root. J Thorac Cardiovasc Surg 1994;108:103742.

6. Thomson DJ, Jamieson WR, Dumesnil JG, et al. Medtronic Mosaic porcine bioprosthesis-an investigational bioprosthesis with satisfactory early clinical performance. Ann Thorac Surg. In press, 1998.

7. Barratt-Boyes BG, Christie GW, Raudkivi PJ. The stentless bioprosthesis: surgical challenges and implications for long term durability. Eur J Cardiothorac Surg 1992;6(suppl 1):39-43.

8. Yoganathan AP, Eberhardt CE, Walker PG. Hydrodynamic performance of the Medtronic Freestyle aortic root bioprosthesis. J Heart Valve Dis 1994;3:571-80.

9. Kirklin JW, Barratt-Boyes BG. Cardiac surgery. 2nd ed. New York: Churchill Livingstone; 1992. p. 527-30.

10. Bloomfield P, Kitchin AH, Wheatley DJ, Waldaum PR, Lutz W, Miller HC. A prospective evaluation of the Björk-Shiley, Hancock and Carpentier-Edwards heart valve prosthesis. Circulation 1986;73:1213-22.

11. Lechner K, Pabinger-Fusching I. Lupus anticoagulants and thrombosis: a study of 25 cases and review of the literature. Haemostasis 1985; 15:254-62.

12. Fann JI, Miller DC, Moore KA, et al. Twenty year clinical experience with porcine bioprostheses. Ann Thorac Surg 1996;62: 1301-11.

13. Broom N, Thomson FJ. Influence of fixation conditions on the performance of glutaraldehyde treated porcine aortic valves: toward a more scientific basis. Thorax 1977;34:166-76.

14. Heng MK, Barratt-Boyes BG, Agnew TM, Brandt PW, Kerr AR, Graham KJ. Isolated mitral replacement with stent-mounted antibiotic-treated aortic allograft valves. J Thorac Cardiovasc Surg 1977;74:230-7.

15. Christie GW, Gavin JB, Barratt-Boyes BG. Graft detachment, a cause of incompetence in stent mounted aortic valve allografts. J Thorac Cardiovasc Surg 1985;90:901-6.

16. Jamieson WR, Burr LH, Miyagishima RT, et al. Structural deterioration in Carpentier-Edwards standard and supra-annular porcine bioprostheses. Ann Thorac Surg 1995;60(suppl 2):241-7.

17. Nistal JF, Hurle A, Gutierrez A, Mazorra F, Revuelta JM. Commissural dehiscence of Carpentier-Edwards mitral bioprosthesis. J Thorac Cardiovasc Surg 1995;110:688-96.

18. Maxwell L, Gavin JB, Barratt-Boyes BG. Uneven host tissue on growth and tissue detachment in stent mounted heart valve allografts and xenografts. Cardiovasc Res 1989;23:709-14.

19. Jamieson WR, Lemieux MD, Sullivan JA, Munro AI, Metras J, Cartier PC. Medtronic Intact porcine bioprosthesis-experience over 10 years. Ann Thorac Surg. In press, 1998.

20. Antretter H. Medtronic Intact porcine bioprosthesis. Ann Thorac Surg 1996;62:940-1.

21. Odell JA. Medtronic Intact porcine bioprosthesis. Ann Thorac Surg 1997;63:1218-9.

22. Christie GW, Barratt-Boyes BG. Comment on: Medtronic Intact bioprosthesis. J Thorac Cardiovasc Surg 1993;106:1219-20.

23. Kadir I, Izzat MB, Wilde P, Reeves B, Bryan AJ, Angellini GD. Dynamic evaluation of the $21 \mathrm{~mm}$ Medtronic Intact aortic bio- 
prosthesis by dobutamine echocardiography. Ann Thorac Surg 1997:63:1128-32.

24. Yun KL, Miller DC, Moore KA, et al. Durability of the Hancock MO bioprosthesis compared with the standard aortic valve bioprosthesis. Ann Thorac Surg 1995;60(suppl 2):221-8.

25. Jamieson WR, Burr LH, Munro AI, et al. The CarpentierEdwards standard porcine bioprosthesis-experience to 21 years. Ann Thorac Surg. In press, 1998.

26. Jamieson WR, Ling H, Burr LH, et al. The Carpentier-Edwards supra-annular porcine bioprosthesis-evaluation over 15 years. Ann Thorac Surg. In press, 1998.
27. Cosgrove DM, Lytle BW, Taylor PC, et al. The CarpentierEdwards pericardial aortic valve: ten-year results. J Thorac Cardiovasc Surg 1995;110:651-62.

28. Aupart MR, Sirinelli AL, Diemont FF, Meurisse YA, Dreyfus $\mathrm{XB}$, Marchand MA. The last generation of pericardial valves in the aortic position: ten year follow-up in 589 patients. Ann Thorac Surg 1996;61:615-20.

29. David TE, Armstrong S, Sun Z. The Hancock II prosthesis at 10 years. Ann Thorac Surg 1995;60(suppl 2):229-34.

30. David TE, Armstrong S, Sun Z, Kuo J. The Hancock II prosthesis at 12 years. Ann Thorac Surg. In press, 1998.

\section{Online-www.aats.org}

Now you can get The Journal of Thoracic and Cardiovascular Surgery online. The Journal online brings you faster delivery time, easy searching of current and back issues, links to PubMed, AATS, WTSA and other important sites, and more. Visit the Journal online today. 